\title{
Risk prediction of ICU readmission in a mixed surgical and medical population
}

Frida Kareliusson ${ }^{1,2}$, Lina De Geer ${ }^{1,2}$ and Anna Oscarsson Tibblin ${ }^{1,2^{*}}$ (1)

\begin{abstract}
Background: Readmission to intensive care units (ICU) is accompanied with longer ICU stay as well as higher ICU, in-hospital and 30-day mortality. Different scoring systems have been used in order to predict and reduce readmission rates.

Methods: The purpose of this study was to evaluate the Stability and Workload Index for Transfer (SWIFT) score as a predictor of readmission. Further, we wanted to study steps and measures taken at the ward prior to readmission.

Results: This was a retrospective study conducted at the mixed surgical and medical ICU at Linköping University Hospital. One thousand sixty-seven patients $>18$ years were admitted to the ICU during 2 years and were included in the study. During the study period, 27 patients were readmitted to the ICU. Readmitted patients had a higher SWIFT score than the non-readmitted (16.1 \pm 6.8 vs. $13.0 \pm 7.5, p=0.03)$ at discharge. The total ICU length of stay was longer ( $7.5 \pm 7.5$ vs. $2.9 \pm 5.1, p=0.004$ ), and the 30-day mortality was higher ( 26 vs. $7 \%, p<0.001$ ) for readmitted patients. Fifty-six percent of readmitted patients were assessed by the critical care outreach service (CCOS) at the ward prior to ICU readmission. A SWIFT score of 15 or more was associated with a significantly higher readmission rate $(p=0.03)$ as well as 30-day mortality $(p<0.001)$ compared to a score of $\leq 14$.
\end{abstract}

Conclusions: A SWIFT score of 15 or more is associated with higher readmission rate and 30-day mortality. The SWIFT score could therefore be used for risk prediction for readmission and mortality at ICU discharge.

Keywords: Intensive care units, Stability and workload index for transfer score, Simplified acute physiology score 3

\section{Background}

The frequency of readmission within $72 \mathrm{~h}$ of intensive care unit (ICU) discharge is one of the most used and well-established measurements of quality in intensive care. Earlier studies have shown that readmitted patients have two to three times longer length of stay in the ICU than non-readmitted patients. In addition, readmitted patients have two to ten times higher risk of death than patients who are not readmitted [1-9]. Internationally, the readmission rate is $6-7 \%[1,2,10]$. Reasons for readmission are most commonly respiratory, cardiovascular and infectious complications. Studies have shown that these complications are related to the original disease in $19-65 \%$ of the cases and due to new complications in $30-40 \%$ of the cases $[1,2]$. The readmission

\footnotetext{
* Correspondence: anna.oscarsson.tibblin@regionostergotland.se 'Department of Anaesthesiology and Intensive Care, Linköping University, Linköping, Sweden

2Department of Medical and Health Sciences, Linköping University, Linköping, Sweden
}

rate is higher at university hospitals than at nonuniversity hospitals, and a risk factor that has been recognized is inadequate follow-up in the ward after ICU discharge. This could be due to a "critical care gap", i.e. a difference in monitoring and care level between the ward and the ICU, resulting in suboptimal care for patients post-ICU. There are conflicting results whether the rate of unpredicted ICU readmission is higher for patients discharged at night $[8,11-13]$. However, a correlation between a high occupancy in the ICU at the time of discharge and the risk of readmission has been shown [13]. In addition, readmitted patients have been shown to have a higher severity of illness, both at admission and discharge from the ICU than non-readmitted patients, with a higher Simplified Acute Physiology Score 3 (SAPS3) as well as Sequential Organ Failure Assessment (SOFA) score in readmitted patients than in those not readmitted $[3,6,8,14]$.

\section{Biomed Central}


Previous studies have shown that patients admitted to the ICU have shown signs of treatable organ failure in the ward prior to ICU admission $[15,16]$. In order to detect signs of deteriorating organ functions at an early stage, scoring systems have been developed for monitoring patients in the ward. One scoring system in clinical use is the Modified Early Warning Score (MEWS), where patients are scored based on their respiratory, circulatory and neurological state, renal function and body temperature [17-19]. Earlier data indicate that MEWS at ICU admission could predict ICU length of stay as well as ICU and 30-day mortality. However, MEWS score at ICU discharge was low and could not predict ICU readmission [20].

The Stability and Workload Index for Transfer (SWIFT) score is a scoring system specifically developed in order to predict readmission to the ICU. SWIFT consists of five different parameters: way of ICU admission, length of ICU stay, respiratory (two parameters) status and neurological status. SWIFT has been found to be able to predict unexpected readmission in both medical and surgical ICUs but has been studied less in a mixed ICU setting.

The aim of this study was therefore to evaluate the prognostic value of the SWIFT score in predicting ICU readmission and mortality in a mixed medical-surgical ICU population. An additional aim was to investigate the effectiveness of a modified SWIFT (M-SWIFT) score including renal function on predicting risk of ICU readmission. Our hypothesis was that the SWIFT score and M-SWIFT could be valuable tools in predicting readmission to the ICU.

\section{Methods}

Ethical approval for this study was provided by the Regional Ethics Committee in the South East of Sweden, Linköping, Sweden on the 12th of December 2012 (number 2012/412-31). Informed consent from patients was waived on the basis that this was not an intervention study.

A retrospective cohort study was conducted at the mixed surgical-medical ICU at the University Hospital, Linköping, Sweden. The hospital is a tertiary teaching hospital with a total of 600 beds and 41,000 admissions yearly. The ICU is an eight-bed ward with 600 admissions yearly. The ICU manages critically ill surgical and medical patients, except for patients undergoing cardiothoracic surgery. The ICU also provides a $24 \mathrm{~h}, 7$ days a week, critical care outreach service (CCOS). The CCOS consists of an anaesthetist or intensive care physician and an intensive care specialist nurse. The criteria for calling the CCOS are MEWS score $>4$, and MEWS has been used as a monitoring tool in the hospital since 2008. All patients $>18$ years admitted to the ICU between 1 January 2011 and 31 December 2012 were included in this study.
All data regarding the critical care admission for all patients are registered in digital medical records, in paper ICU charts, later scanned as attachments to the digital records, and in the Swedish Intensive Care Registry (SIR). Information about age, gender, time of admittance and discharge, length of ICU stay, source of admission, admitting ward, accepting ward after discharge, SAPS3 on admittance, SOFA score at discharge, comorbidities, diagnoses and treatment strategy as well as ICU occupancy was collected from SIR.

The SWIFT score consists of five variables: original source of admission, length of ICU stay, last measured partial pressure of oxygen in arterial blood $\left(\mathrm{PaO}_{2}\right) /$ fraction of inspired oxygen $\left(\mathrm{FiO}_{2}\right)(\mathrm{mmHg})$ ratio, last measured $\mathrm{PaCO}_{2}(\mathrm{mmHg})$ and Glasgow Coma Scale (GCS) at discharge, all seen in Table 1. The SWIFT score was calculated for all patients discharged to a ward. The $\mathrm{PaO}_{2} / \mathrm{FiO}_{2}$ ratio and $\mathrm{PaCO}_{2}$ were extracted from the last arterial blood gas taken before ICU discharge. The GCS at discharge was collected from the paper ICU chart. In cases where GCS was missing in the charts, it was calculated from discharge entries in the medical records. The MEWS score at discharge was also calculated based on information in ICU charts and medical records. For some patients, the MEWS score at discharge was already reported in the ICU chart, and in these cases, this value

\begin{tabular}{ll}
\multicolumn{2}{l}{ Table $\mathbf{1}$ The stability for workload and transfer score } \\
\hline $\begin{array}{l}\text { Variable } \\
\text { Original source of this ICU admission }\end{array}$ & SWIFT point \\
$\quad$ Emergency department & 0 \\
Transfer from a ward or outside hospital & 8 \\
(any type of nursing unit) & \\
Total ICU length of stay (duration in days) & 0 \\
$<2$ & 1 \\
$2-10$ & 14 \\
$>10$ & 0 \\
Last measured PaO $/$ FiO 2 ratio (during this ICU admission) & \\
$>400$ & 5 \\
$<400$ and $>150$ & 10 \\
$<150$ and $>100$ & 13 \\
$<100$ & \\
Glasgow Coma Scale at time of ICU discharge & 0 \\
$>14$ & 6 \\
$11-14$ & \\
$8-10$ & \\
$<8$ &
\end{tabular}


was used. A M-SWIFT score was calculated for all patients discharged to a ward. M-SWIFT was calculated using the SWIFT score, with an additional assessment of renal function. Patients with a urine output $<500 \mathrm{~mL} /$ day and/or a creatinine level $>170 \mu \mathrm{mol} / \mathrm{L}$ (equalling a SOFA renal score $>2$ ) received five additional points. Readmission was defined as an unexpected readmission to the ICU within $72 \mathrm{~h}$ after ICU discharge. For these patients, medical records were thoroughly studied, regarding the time after discharge until readmission. The alteration in MEWS score at the ward, if the CCOS had been called upon, interventions at the ward, treatment strategies and reason for readmission were documented.

\section{Statistical analysis}

The comparison of data such as age, length of ICU stay, SAPS3, SOFA score, SWIFT and M-SWIFT scores as well as numerical variables included in the SWIFT and SOFA scores was made with unpaired Student's $t$ test. Pearson's chi-squared test was used to compare categorical data such as gender, original source of admission, ward at admission, mortality, treatment strategy and the presence of comorbidity. The MEWS score was compared with a two-sample Mann-Whitney $U$ test. A $p$ value $<0.05$ was considered significant. Data analysis was performed in STATA version 12.1 (StataCorp. LP, College Station, Texas, USA) and SPSS version 20 (IBM corp, Armonk, New York, USA).

\section{Results}

\section{Study population}

During the study period, 1244 patients were admitted to the ICU. One hundred seventy-four patients (14\%) were aged $<18$ years. Three patients were defined as postoperative patients and were therefore excluded from the study. Of the total adult population, 140 patients (13\%) were discharged to another ICU. Ninety-seven patients (9\%) died during the ICU stay. Thirty-four patients (3\%) were discharged to another hospital, and 10 patients $(1 \%)$ were discharged to their home. A total of 786 patients (74 \%) were discharged to a ward in the hospital and 53 of these (7\%) had treatment strategies, i.e. at discharge, treating physicians had decided not to readmit the patient to the ICU in case of deterioration. The number of patients at risk of readmission was therefore 733 .

\section{ICU admission}

Out of 1067 adult patients admitted to the ICU, $332 \mathrm{pa}$ tients (31\%) were admitted from a ward, 281 patients (26\%) from the emergency department, 244 patients (23\%) from the operating theatre, 101 patients (9\%) from another ICU, 98 patients (9\%) from a ward at another hospital and 11 patients $(1 \%)$ were obstetric patients (Table 2). Five hundred sixty-three patients (53\%) were
Table 2 Demographic characteristics of studied patients

\begin{tabular}{|c|c|c|}
\hline Variables & $n=1067$ & $95 \% \mathrm{Cl}$ \\
\hline Age, year, mean (SD) & $57(19)$ & $56-58$ \\
\hline \multicolumn{3}{|l|}{ Gender, $n(\%)$} \\
\hline Male & $613(57)$ & \\
\hline Female & $454(43)$ & \\
\hline \multicolumn{3}{|l|}{ Original source of admission, $n(\%)$} \\
\hline Emergency department & $281(26)$ & \\
\hline Other ICU & $101(9)$ & \\
\hline Other hospital & $98(9)$ & \\
\hline Operating theatre & $244(23)$ & \\
\hline Ward & $332(31)$ & \\
\hline Delivery ward & $11(1)$ & \\
\hline \multicolumn{3}{|l|}{ Ward at admission, $n(\%)$} \\
\hline Medical wards & $458(43)$ & \\
\hline Surgical wards & $563(53)$ & \\
\hline Oncologic wards & $46(4)$ & \\
\hline \multicolumn{3}{|l|}{ Severity of illness } \\
\hline SOFA score, mean (SD) & 4.0 & $3.8-4.2$ \\
\hline SAPS3, mean (SD) & 55.1 & $54.1-56.1$ \\
\hline SWIFT score, mean (SD) & 14.0 & 13.4-14.6 \\
\hline MEWS, mean (SD) & 1.9 & $1.8-2.0$ \\
\hline Treatment strategy, $n(\%)$ & $114(11)$ & \\
\hline \multicolumn{3}{|l|}{ Outcomes } \\
\hline ICU mortality, $n(\%)$ & $97(9)$ & \\
\hline 30-day mortality, $n$ (\%) & $226(21)$ & \\
\hline Length of ICU stay, day, mean (SD) & 3.7 & $3.3-4.0$ \\
\hline ICU Readmission, $n$ (\%) & $27(2.5)$ & \\
\hline
\end{tabular}

Cl confidence interval

surgical, 458 patients ( $43 \%$ ) were medical, and 46 patients (4\%) were oncological patients. The mean length of stay at the ICU were 3.7 days (95\% CI 3.3-4.0) (Table 2).

\section{ICU readmission}

Twenty-seven patients $(2.5 \%)$ were readmitted to the ICU within $72 \mathrm{~h}$ after discharge (Fig. 1). When excluding all patients discharged to another ICU, to another hospital, to their home and those with treatment strategies, the readmission rate was $3.8 \%$. Readmitted patients were significantly older than patients who were not readmitted ( $65 \pm 12$ vs. $54 \pm 19, p=0.005)$ (Table 3). In addition, readmitted patients had a higher SOFA score $(4.4 \pm 2.8$ vs. $3.0 \pm 2.2, p=0.01)$ and a higher MEWS at discharge $(2.3 \pm 1.3$ vs. $1.8 \pm 1.2, p=0.03)$ than nonreadmitted patients (Table 4). Readmitted patients tended to more often be women, more often been admitted from a hospital ward and more often to be surgical patients than non-readmitted, however, not statistically significant (Table 3). Readmitted patients were more 


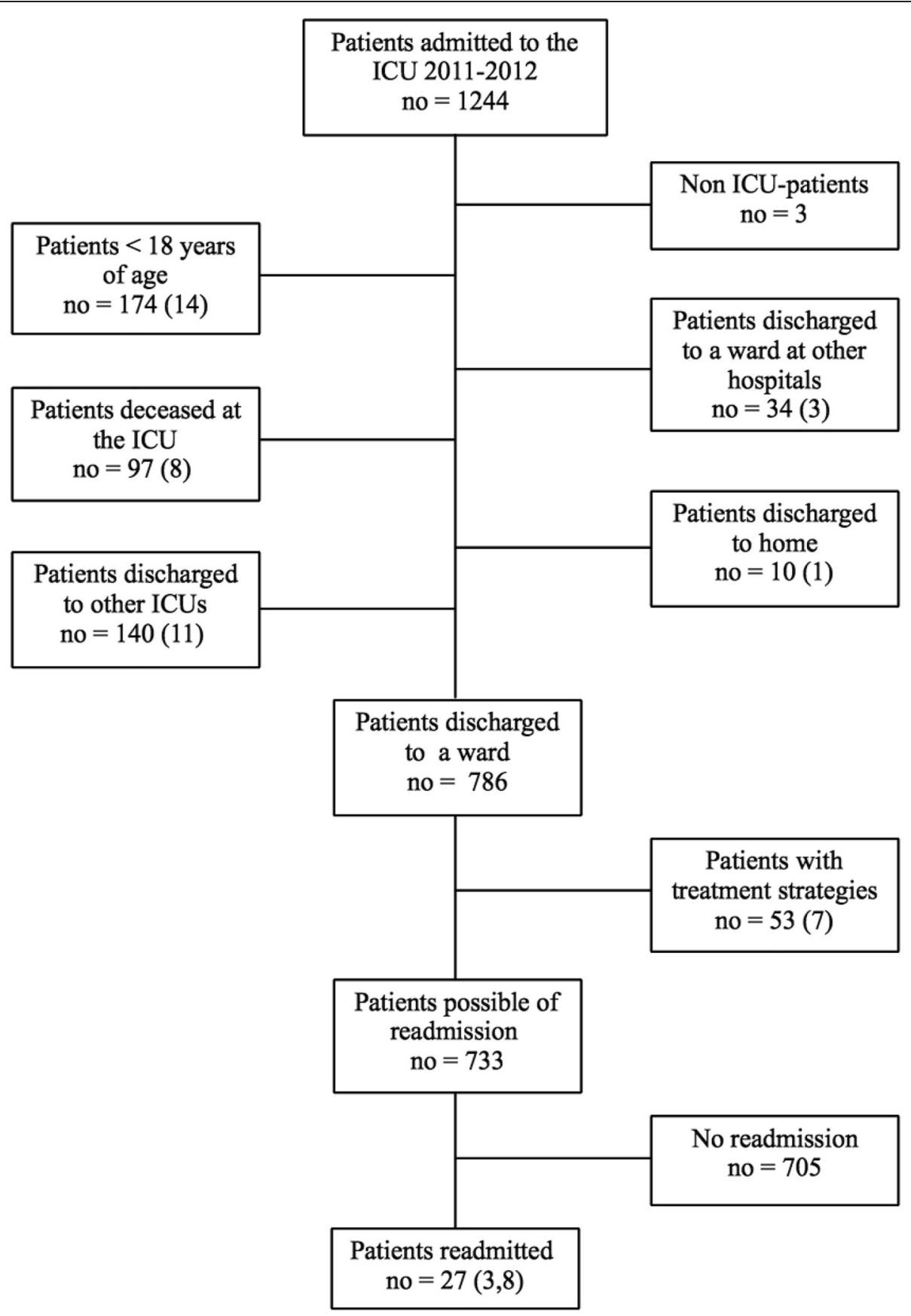

Fig. 1 Patient discharge flowchart

often immunocompromised, 1 patient (4\%) compared to 13 patients $(2 \%)(p=0.05)$. Kidney failure was also more common among readmitted patients (6 (23\%) vs. 54 (8\%), $p=0.05$ ) (Table 3). At discharge, readmitted patients had a significantly higher SWIFT score (16.1 \pm 6.8 vs. $13.0 \pm 7.5, p=0.03$ ) than non-readmitted. When comparing different parameters of the SWIFT score, readmitted patients had a significantly lower $\mathrm{PaO}_{2} / \mathrm{FiO}_{2}$ ratio $(p=0.03)$ than non-readmitted patients. $\mathrm{PCO}_{2}$ did not differ between the readmitted and nonreadmitted patients when comparing means. However, readmitted patients were significantly more likely to have a $\mathrm{PCO}_{2}>45 \mathrm{mmHg}$ than non-readmitted patients $(p=0.04)$. Readmitted patients also had a significantly higher M-SWIFT score than non-readmitted patients $(17.6 \pm 7.3$ vs. $13.5 \pm 7.7, p=0.007)$ (Table 4$)$. The median (interquartile range (IQR)) ICU occupancy during the study period was $78 \%(66-90 \%)$. When patients 
Table 3 Characteristics of readmitted and non-readmitted patients

\begin{tabular}{|c|c|c|c|c|c|}
\hline \multirow[t]{2}{*}{ Variables } & \multirow[t]{2}{*}{ Readmission $(n=27)$} & \multirow{2}{*}{\multicolumn{2}{|c|}{ No. of readmission $(n=705)$}} & \multirow[b]{2}{*}{$95 \% \mathrm{Cl}$} & \multirow[t]{2}{*}{$p$ value } \\
\hline & & & & & \\
\hline Age, years, mean & 64.7 & $60-70$ & 54.2 & $53-56$ & 0.005 \\
\hline Gender, $n(\%)$ & & & & & 0.38 \\
\hline Male & $400(57)$ & & $13(48)$ & & \\
\hline Female & $305(43)$ & & $14(52)$ & & \\
\hline Original source of admission, $n(\%)$ & & & & & 0.42 \\
\hline Emergency department & $4(15)$ & & $210(29)$ & & \\
\hline Other ICU & $1(4)$ & & $36(5)$ & & \\
\hline Other hospital & $2(7)$ & & $42(6)$ & & \\
\hline Operating theatre & $6(22)$ & & $192(25)$ & & \\
\hline Ward & $14(52)$ & & $216(31)$ & & \\
\hline Delivery ward & $0(0)$ & & $9(1)$ & & \\
\hline Ward at admission, $n$ (\%) & & & & & 0.26 \\
\hline Medical wards & $7(26)$ & & $288(41)$ & & \\
\hline Surgical wards & $19(70)$ & & $404(57)$ & & \\
\hline Oncologic wards & $1(4)$ & & $13(2)$ & & \\
\hline \multicolumn{6}{|l|}{ Comorbidity, n (\%) } \\
\hline Immunodeficiency & $1(4)$ & & $13(2)$ & & 0.05 \\
\hline Chronic obstructive pulmonary disease & $1(4)$ & & $46(6)$ & & 0.59 \\
\hline Kidney failure & $6(23)$ & & $54(8)$ & & 0.005 \\
\hline Chronic & $2(7)$ & & $10(1)$ & & \\
\hline Liver failure & $0(0)$ & & $6(1)$ & & 0.64 \\
\hline Heart failure & $0(0)$ & & $22(3)$ & & 0.36 \\
\hline Malignancy & $4(15)$ & & $84(12)$ & & 0.59 \\
\hline Sepsis & $3(12)$ & & $75(11)$ & & 0.88 \\
\hline \multicolumn{6}{|l|}{ Outcome } \\
\hline Total length of ICU stay, days, mean (SD) & $7.5(7.5)$ & & $2.9(5.1)$ & & 0.004 \\
\hline Length of ICU stay, primary admission, mean (SD) & $3.0(5.2)$ & & $2.8(4.1)$ & & 0.88 \\
\hline ICU mortality, n (\%) & $6(22)$ & & na & & \\
\hline 30-day mortality, $n(\%)$ & $7(26)$ & & $50(7)$ & & $<0.001$ \\
\hline Treatment strategy, n (\%) & $6(22)$ & & na & & \\
\hline
\end{tabular}

$\mathrm{Cl}$ confidence interval

who were later readmitted were discharged, the median (IQR) ICU occupancy was $88 \%(75-100 \%, p=0.002)$.

\section{Readmitted patient's data on ward}

At discharge, three $(11 \%)$ of the 27 readmitted patients had a MEWS score of at least four, which is the criterion for calling CCOS at our hospital. For these three patients, CCOS were called two to three times after ICU discharge. Fifteen readmitted patients $(56 \%)$ had a MEWS score $>4$ at the ward and therefore reached the criteria for a CCOS consultation. Nine $(60 \%)$ of these 15 patients were assessed by the CCOS. Of the 12 patients that had MEWS $<4,6$ patients (50\%) had a CCOS consultation. Eight of the readmitted patients (30\%) showed confusion and/or anxiety at the ward. At the ward, 16 patients (59\%) had respiratory interventions such as suction of the airways, CPAP or inhalations. Thirteen patients $(48 \%)$ had circulatory interventions such as extra fluids and/or diuretics. Two patients (7 \%) had infectious interventions with a change in antibiotic treatment. Ten of the 27 patients (37\%) were readmitted due to circulatory complications, 15 patients $(56 \%)$ to respiratory complications and 2 patients $(7 \%)$ to neurological complications (Fig. 2). Of the 10 patients readmitted for circulatory reasons, $5(50 \%)$ had a circulatory intervention at the ward and $3(30 \%)$ had a respiratory 
Table 4 Severity of illness scores in readmitted and non-readmitted patients

\begin{tabular}{|c|c|c|c|c|c|}
\hline \multirow[t]{2}{*}{ Variables } & \multirow[t]{2}{*}{ Readmission $(n=27)$} & \multicolumn{3}{|c|}{ No. of readmission $(n=705)$} & \multirow[t]{2}{*}{$p$ value } \\
\hline & & $95 \% \mathrm{Cl}$ & & $95 \% \mathrm{Cl}$ & \\
\hline SAPS3, mean (SD) & $56.0(11.6)$ & $51.4-60.6$ & $50.5(14.4)$ & $49.5-51.6$ & 0.50 \\
\hline MEWS, mean (SD) & $2.3(1.3)$ & & $1.8(1.2)$ & & 0.03 \\
\hline SWIFT score, mean (SD) & $16.1(6.8)$ & $13.4-18.9$ & $13.0(7.5)$ & $12.4-13.6$ & 0.03 \\
\hline Length of ICU stay, dy, mean (SD) & $3.0(5.2)$ & $1.2-4.5$ & $2.8(4.1)$ & $2.6-3.4$ & 0.88 \\
\hline Source of admission $n(\%)$ & & & & & 0.09 \\
\hline Emergency & $4(15)$ & & $210(30)$ & & \\
\hline Other source & $23(85)$ & & $495(70)$ & & \\
\hline $\mathrm{PaO}_{2} / \mathrm{FiO}_{2} \mathrm{mmHg}$, mean (SD) & $287(109)$ & $244-330$ & $338(119)$ & $329-348$ & 0.03 \\
\hline GCS at discharge & $14.7(0.5)$ & $14.5-14.9$ & $14.7(1.2)$ & $14.6-14.8$ & 0.91 \\
\hline $\mathrm{PCO}_{2}$ mmHg, mean (SD) & $41.0(8.0)$ & $37.8-44.2$ & $39.7(8.2)$ & $39.1-40.3$ & 0.42 \\
\hline $\mathrm{PCO}_{2} \mathrm{mmHg}, n(\%)$ & & & & & 0.04 \\
\hline$<45$ & $18(67)$ & & $526(83)$ & & \\
\hline$>45$ & $9(33)$ & & $111(17)$ & & \\
\hline Modified SWIFT score, mean (SD) & $13.5(7.7)$ & & $17.6(7.4)$ & & 0.007 \\
\hline SOFA score, mean (SD) & $4.4(2.8)$ & $3.3-5.6$ & $3.0(2.2)$ & $2.8-3.2$ & 0.001 \\
\hline Respiration & $2.1(1.1)$ & & $1.4(1.1)$ & & 0.002 \\
\hline Coagulation & $0.8(1.1)$ & & $0.4(0.8)$ & & 0.07 \\
\hline Liver & $0.3(0.6)$ & & $0.3(0.7)$ & & 0.86 \\
\hline Cardiovascular & $0.3(0.7)$ & & $0.3(0.6)$ & & 0.78 \\
\hline CNS & $0.2(0.5)$ & & $0.2(0.6)$ & & 0.57 \\
\hline Renal & $0.8(1.1)$ & & $0.4(0.8)$ & & 0.06 \\
\hline
\end{tabular}

MEWS Modified Early Warning Score, SAPS3 Simplified Acute Physiology Score 3, SOFA Sequential Organ Failure Assessment score, SWIFT Stability and Workload Index for Transfer score

intervention. Of the 15 patients readmitted due to respiratory reasons, $12(80 \%)$ had respiratory interventions and 8 (53\%) had circulatory interventions at the ward.

\section{Outcome}

The total length of ICU stay was significantly higher among readmitted patients $(7.5 \pm 7.5$ vs. $2.9 \pm 5.1, p=0.004)$
(Table 3). ICU mortality was significantly higher in readmitted patients compared to the whole ICU population (21\% vs. $9 \%, p=0.02)$. The mortality after 30 days was also significantly higher in readmitted patients $7(26 \%)$ compared to $50(7 \%)$ of the non-readmitted, $p<0.001$ (Table 3). The 30-day mortality was $21 \%$. Patients discharged to a ward without treatment strategies with a SWIFT $\geq 15$ had a

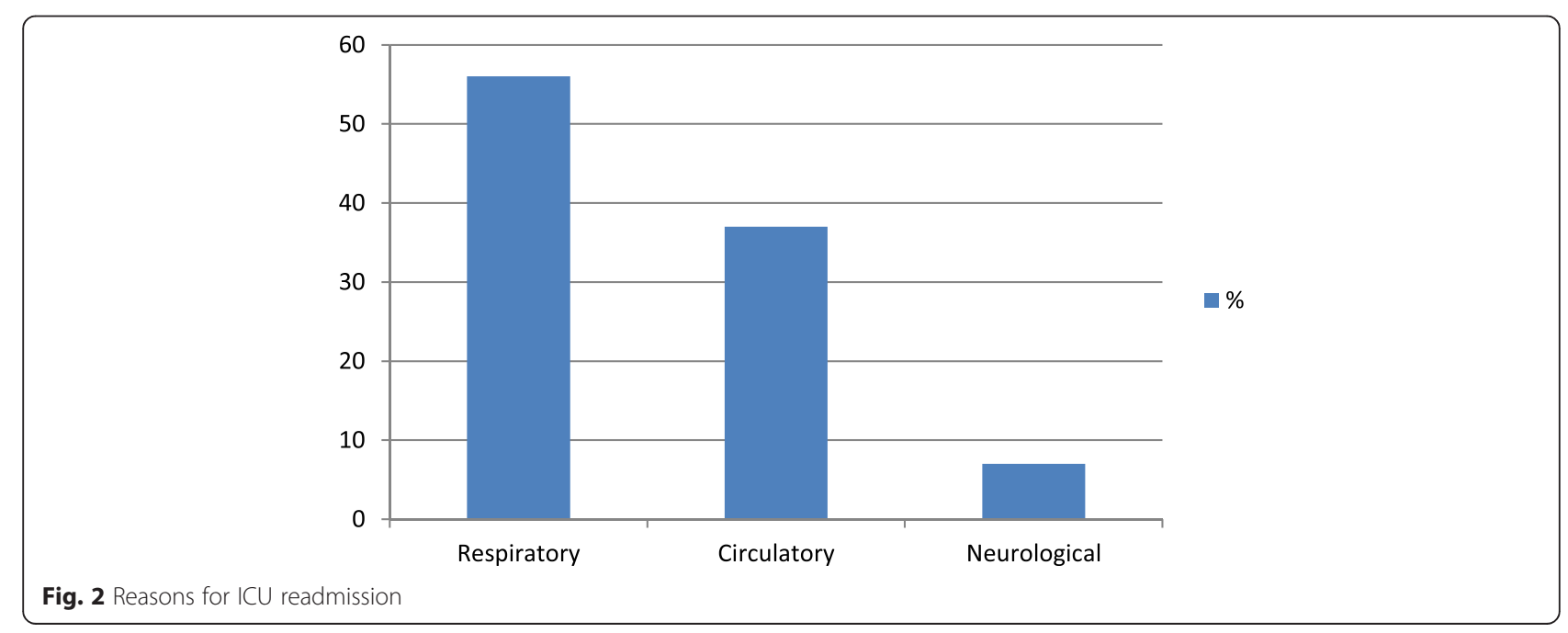


significantly higher readmission frequency as well as 30-day mortality rate compared to patients with a SWIFT $\leq 14$ (Table 5). A M-SWIFT $\geq 15$ compared to a M-SWIFT $\leq 14$ was also associated with a significant higher frequency of readmission and 30-day mortality (Table 5).

\section{Discussion}

In this study, we found that patients readmitted to the ICU had a significantly higher SWIFT score as well as M-SWIFT at ICU discharge than non-readmitted patients. We found that readmitted patients had higher MEWS and SOFA scores than non-readmitted patients, indicating a higher severity of illness at discharge. Furthermore, a SWIFT as well as M-SWIFT score $\geq 15$ was associated with higher rate of readmission and 30-day mortality. This indicates the need for caution when discharging patients above this cut-off.

In line with previous results, we found a significant difference in respiratory parameters between readmitted and non-readmitted patients at discharge, with decreased $\mathrm{PaO}_{2} / \mathrm{FiO}_{2}$ ratio in the readmitted [11, 21, 22]. In addition, when studying the individual parameters in SOFA, the respiratory score was significantly higher in readmitted patients. Also, $56 \%$ of readmissions were due to respiratory reasons. Thus, respiratory functions seem to be central to the risk of ICU readmission, and our results also suggest that patients are discharged without sufficiently stable respiratory functions. In addition, our results indicate a possible weakness in wards regarding specific respiratory support after critical care.

In addition to a reduced $\mathrm{PaO}_{2} / \mathrm{FiO}_{2}$ ratio, we found that readmitted patients had a significantly higher rate of kidney failure, acute as well as chronic, than nonreadmitted patients. Three previous studies found similar results regarding chronic renal disease [2, 6, 23]. One earlier study found that low urine output and abnormal creatinine levels were a risk factor for readmission [22]. Since kidney injury is a well-described and strong prognostic indicator for poor outcome after intensive care, a scoring system for risk of ICU readmission should logically include a parameter for renal function. Based on these data, we decided to add a renal parameter to the SWIFT score. We found that readmitted patients had a higher modified SWIFT score than non-readmitted patients, indicating that renal function is an important factor for readmission. We believe that a modified SWIFT,

Table 5 Outcome in relation to SWIFT score

\begin{tabular}{llll}
\hline Variables & $\begin{array}{l}\text { SWIFT } \leq 14 \\
(n=466)\end{array}$ & $\begin{array}{l}\text { SWIFT }=\geq 15 \\
(n=195)\end{array}$ & $\begin{array}{l}p \\
\text { value }\end{array}$ \\
\hline Readmission, $n(\%)$ & $14(3)$ & $13(7)$ & 0.03 \\
30-days mortality, $n(\%)$ & $26(6)$ & $33(17)$ & $<0.001$ \\
\hline
\end{tabular}

SWIFT Stability and Workload Index for Transfer score including renal function, would increase the accuracy of the score in predicting readmission. Further and larger studies are needed to test this hypothesis. Also, a prospective study assessing the rate of readmissions before and after the introduction of SWIFT score or modified SWIFT score would indeed be interesting.

Readmitted patients had a higher severity of illness when discharged from the ICU, indicating that these patients may have been discharged somewhat prematurely. This correlates with earlier studies showing that 22-42\% of unexpected ICU readmissions in patients with a reduced physiological reserve are due to premature discharge $[22,24]$. The reason behind early discharge is beyond the scope of this study, but the lack of ICU beds has, in other studies, been presented as an important cause $[6,9,11,23,25]$. There are no formal ICU discharge criteria at the ICU studied, but our results indicate, in line with these previous studies, that ICU occupancy may have contributed to the decision to discharge the patients.

In order to reduce unexpected admissions to the ICU by optimizing the treatment of patients in the ward, CCOS has been introduced in many hospitals worldwide. The CCOS, often consisting of an intensivist and an intensive care nurse, can be called upon by ward staff when a patient meets specific physiological criteria. The introduction of these teams has been shown to reduce unexpected ICU admissions [26, 27], and even to reduce ICU readmissions $[28,29]$ and mortality in readmitted patients [30]. Another study showed that patients discharged from the ICU and later readmitted were more likely to need a CCOS consultation, and patients meeting the CCOS criteria had 25 times higher risk for readmission [31]. The CCOS criterion at Linköping University Hospital is primarily a MEWS score $>4$. Interestingly, only $60 \%$ of the patients meeting this criterion were assessed by the CCOS, corresponding to results found in another study [31]. The reason for this is unclear, but possible reasons may be that CCOS consultations are not formally obliged and may have been replaced by a direct physician to physician contact, or even overlooked. Also, some patients may have been readmitted after an emergency incident at the ward, not preceded by a CCOS consultation. Furthermore, $50 \%$ of patients having MEWS $<4$ had a CCOS consultation, which might indicate that the CCOS was called upon for general worries of the patient or concerns regarding parameters not considered in the MEWS score. The ability of the ward to consult the CCOS team for other reasons than formal CCOS criteria may have contributed to the low readmission rate seen in this study.

A number of studies have evaluated different scoring systems for predicting readmission and death in ICU patients. In this study, we have focused on the SWIFT score, the MEWS score and the SOFA score as well as the M-SWIFT score, all of which were significantly 
higher in patients who were readmitted than in those who were not. The different scores use different parameters, but all overlap to some degree. The discharge of a patient may therefore be reconsidered if the patient scores high in all scales and when having a SWIFT score of 15 or more in particular.

Internationally, the ICU readmission rate is 6-7 \% $[1,2,10]$. In contrast, the readmission rate in this study was low (2.5\%). Differences in ICU admission and discharge criteria as well as treatment options in the wards are possible reasons behind these differences, and in practice, a $0 \%$ readmission rate is scarcely a realistic goal. However, our results indicate that among readmitted patients are some in whom readmission could have been avoided if their severity of illness had been more thoroughly assessed before discharge or if monitoring and treatment at the ward had been optimised. In view of this, we believe that the ICU readmission rate could be decreased further, possibly by a more thorough assessment of the risk of readmission in all patients discharged, followed by a formalised CCOS consultation in those at risk of readmission.

\section{Limitations}

This study has several limitations. First, this was a singlecentre study, and its generalizability is therefore limited. Second, the population of readmitted patients was small compared to international data. Third, this was a retrospective observational study. Therefore, there was no control group when studying factors in the ward prior to readmission.

\section{Conclusions}

In conclusion, we found that readmitted patients had a higher SWIFT as well as M-SWIFT score. Readmitted patients were more severely ill than non-readmitted patients at discharge and may have been discharged from the ICU too early. Readmitted patients had longer ICU length of stay and higher 30-day mortality, and SWIFT score could be used as a predictor of 30-day mortality. ICU discharge should therefore be reconsidered in patients with a SWIFT score of at least 15. Larger studies are needed to prospectively investigate the SWIFT and M-SWIFT scores as predictors of readmission and to further study the period at ward prior to readmission.

\footnotetext{
Abbreviations

CCOS: critical care outreach service; $\mathrm{Cl}$ : confidence interval; $\mathrm{FiO}_{2}$ : fraction of inspired oxygen; GCS: Glasgow Coma Scale; ICU: intensive care unit; MEWS: Modified Early Warning Score; M-SWIFT: Modified Stability and Workload Index for Transfer score; PaCO2: partial pressure of carbon dioxide in arterial blood; $\mathrm{PaO}_{2}$ : partial pressure of oxygen in arterial blood; SAPS3: Simplified Acute Physiology Score 3; SOFA: Sequential Organ Failure Assessment score; SWIFT: Stability and Workload Index for Transfer score.
}

\section{Competing interests}

The authors declare that they have no competing interests.

\section{Authors' contributions}

FK participated in designing the study, was mainly responsible for collecting the data, participated in the data analysis and was mainly responsible for writing the manuscript. LDG and AOT participated in designing the study, in the data collection and analysis and in writing the manuscript. All authors read and approved the final manuscript.

\section{Acknowledgments}

We thank Mats Fredrikson, PhD and statistical consultant at Linköping Academic Research Centre (LARC), for his help with the statistical analysis. The study was supported by grants from the County Council of Östergötland, Sweden. The funding agent was not involved in the study design, data collection, analysis or interpretation, or in writing or submitting the manuscript.

Received: 15 April 2015 Accepted: 12 June 2015

Published online: 26 June 2015

\section{References}

1. Chen LM, Martin CM, Keenan SP, Sibbald WJ. Patients readmitted to the intensive care unit during the same hospitalization: clinical features and outcomes. Crit Care Med. 1998;26:1834-41.

2. Cooper GS, Sirio CA, Rotondi AJ, Shepardson LB, Rosenthal GE. Are readmissions to the intensive care unit a useful measure of hospital performance? Med Care. 1999;37:399-408.

3. Durbin CG, Kopel RF. A case-control study of patients readmitted to the intensive care unit. Crit Care Med. 1993;21:1547-53.

4. Rosenberg AL, Hofer TP, Hayward RA, Strachan C, Watts CM. Who bounces back? Physiologic and other predictors of intensive care unit readmission. Crit Care Med. 2001;29:511-8.

5. Alban RF, Nisim AA, Ho J, Nishi GK, Shabot MM. Readmission to surgical intensive care increases severity-adjusted patient mortality. J Trauma: Injury, Infection, and Critical Care. 2006;60(5):1027-31.

6. Kaben A, Corrêa F, Reinhart K, Settmacher U, Gummert J, Kalff R, et al. Readmission to a surgical intensive care unit: incidence, outcome and risk factors. Crit Care. 2008;12(5):R123.

7. Franklin C, Jackson D. Discharge decision-making in a medical ICU: characteristics of unexpected readmissions. Crit Care Med. 1983;11(2):61-6.

8. Renton J, Pilcher DV, Santamaria JD, Stow P, Bailey M, Hart G, et al. Factors associated with increased risk of readmission to intensive care in Australia. Intensive Care Med. 2011;37(11):1800-8.

9. Chan K-S, Tan C-K, Fang C-S, Tsai C-L, Hou C-C, Cheng K-C, et al. Readmission to the intensive care unit: an indicator that reflects the potential risks of morbidity and mortality of surgical patients in the intensive care unit. Surg Today. 2009:39(4):295-9.

10. Rosenberg AL, Watts $C$. Patients readmitted to ICUs*: a systematic review of risk factors and outcomes. Chest. 2000;118:492-502.

11. Ouanes I, Schwebel C, Francais A, Bruel C, Philippart F, Vesin A, et al. A model to predict short-term death or readmission after intensive care unit discharge. J Crit Care. 2012;27:422. e1-9.

12. Hanane T, Keegan MT, Seferian EG, Gajic O, Afessa B. The association between nighttime transfer from the intensive care unit and patient outcome. Crit Care Med. 2008;36(8):2232-7.

13. Chrusch CA, Olafson KP, McMillan PM, Roberts DE, Gray PR. High occupancy increases the risk of early death or readmission after transfer from intensive care. Crit Care Med. 2009;37:2753-8.

14. Frost SA, Alexandrou E, Bogdanovski T, Salamonson Y, Davidson PM, Parr MJ, et al. Severity of illness and risk of readmission to intensive care: a meta-analysis. Resuscitation. 2009:80:505-10.

15. Goldhill DR, White SA, Sumner A. Physiological values and procedures in the $24 \mathrm{~h}$ before ICU admission from the ward. Anaesthesia. 1999;54(6):529-34.

16. Kause J, Smith G, Prytherch D, Parr M, Flabouris A, Hillman K. A comparison of antecedents to cardiac arrests, deaths and emergency intensive care admissions in Australia and New Zealand, and the United Kingdom-the ACADEMIA study. Resuscitation. 2004;62(3):275-82.

17. Gardner-Thorpe J, Love N, Wrightson J, Walsh S, Keeling N. The value of Modified Early Warning Score (MEWS) in surgical in-patients: a prospective observational study. Ann R Coll Surg Engl. 2006;88(6):571-5.

18. Burch VC, Tarr G, Morroni C. Modified Early Warning Score predicts the need for hospital admission and inhospital mortality. Emerg Med J. 2008;25(10):674-8. 
19. Subbe CP, Davies RG, Williams E, Rutherford P, Gemmell L. Effect of introducing the Modified Early Warning score on clinical outcomes, cardio-pulmonary arrests and intensive care utilisation in acute medical admissions. Anaesthesia. 2003;58(8):797-802.

20. Reini K, Fredrikson M, Oscarsson A. The prognostic value of the Modified Early Warning Score in critically ill patients: a prospective, observational study. Eur J Anaesthesiol. 2012;29:152-7.

21. Gajic O, Malinchoc M, Comfere TB, Harris MR, Achouiti A, Yilmaz M, et al. The Stability and Workload Index for Transfer score predicts unplanned intensive care unit patient readmission: initial development and validation. Crit Care Med. 2008;36:676-82.

22. Snow N, Bergin KT, Horrigan TP. Readmission of patients to the surgical intensive care unit: patient profiles and possibilities for prevention. Crit Care Med. 1985;13:961-4.

23. Metnitz PGH, Fieux F, Jordan B, Lang T, Moreno R, Le Gall J-R. Critically ill patients readmitted to intensive care units-lessons to learn? Intensive Care Med. 2003;29(2):241-8

24. Baigelman W, Katz R, Geary G. Patient readmission to critical care units during the same hospitalization at a community teaching hospital. Intensive Care Med. 1983;9:253-6.

25. Campbell AJ, Cook JA, Adey G, Cuthbertson BH. Predicting death and readmission after intensive care discharge. Br J Anaesth. 2008;100:656-62.

26. Bellomo R, Goldsmith D, Uchino S, Buckmaster J, Hart G, Opdam H, et al. Prospective controlled trial of effect of medical emergency team on postoperative morbidity and mortality rates. Crit Care Med. 2004;32:916-21.

27. Bristow PJ, Hillman KM, Chey T, Daffurn K, Jacques TC, Norman SL, et al. Rates of in-hospital arrests, deaths and intensive care admissions: the effect of a medical emergency team. Med J Aust. 2000;173:236-40.

28. Al-Qahtani S, Al-Dorzi HM, Tamim HM, Hussain S, Fong L, Taher S, et al. Impact of an intensivist-led multidisciplinary extended rapid response team on hospital-wide cardiopulmonary arrests and mortality. Crit Care Med. 2013;41(2):506-17.

29. Ball C, Kirkby M, Williams S. Effect of the critical care outreach team on patient survival to discharge from hospital and readmission to critical care: non-randomised population based study. BMJ. 2003;327(7422):1014.

30. Garcea G, Thomasset S, McClelland L, Leslie A, Berry DP. Impact of a critical care outreach team on critical care readmissions and mortality. Acta Anaesthesiol Scand. 2004;48(9):1096-100.

31. Makris N, Dulhunty JM, Paratz JD, Bandeshe H, Gowardman JR. Unplanned early readmission to the intensive care unit: a case-control study of patient, intensive care and ward-related factors. Anaesth Intensive Care. 2010;38:723-31.

\section{Submit your next manuscript to BioMed Central and take full advantage of:}

- Convenient online submission

- Thorough peer review

- No space constraints or color figure charges

- Immediate publication on acceptance

- Inclusion in PubMed, CAS, Scopus and Google Scholar

- Research which is freely available for redistribution 